\title{
Gastrointestinal Image: A True Giant Transverse Colon Diverticulum
}

\author{
Marek Olakowski • Beata Jabłońska • \\ Andrzej Lekstan • Weronika Szczęsny-Karczewska • \\ Joanna Pilch-Kowalczyk • Maciej Kohut
}

Received: 23 November 2010 / Accepted: 2 February 2011 /Published online: 15 March 2011

(C) The Author(s) 2011. This article is published with open access at Springerlink.com

Abstract Giant colonic diverticulum is an extremely rare condition in colonic diverticular disease. More than $90 \%$ of giant colonic diverticula are found in the sigmoid colon. Inflammatory and pseudodiverticula are the most frequent. Only one case of a true diverticulum of the transverse colon has been reported in the literature.

Case Report We report a case of a 22 -year-old woman presenting with constipation and meteorism from childhood. A plain abdominal X-ray showed a round radiolucent air-filled cyst. Barium enema revealed a single, large diverticulum of the transverse colon. An extended right hemicolectomy with primary end-to-end anastomosis was performed. The postoperative course was uneventful, and she was discharged in 1 week without any complications. Histopathology showed a true diverticulum containing all layers of the colon.

Keywords Giant colonic diverticulum · Transverse colon · Congenital duplication

\section{Case History}

In July 2010, a 22-year-old woman was admitted with a history of constipation and meterorism that were longstanding from childhood. The loss of weight and anorexia

M. Olakowski • B. Jabłońska $(\bowtie) \cdot$ A. Lekstan

Department of Digestive Tract Surgery,

Medical University of Silesia,

Medyków 14 St,

40-752 Katowice, Poland

e-mail: bjablonska@poczta.onet.pl

W. Szczęsny-Karczewska

Department of Pathomorphology, Medical University of Silesia, Katowice, Poland

J. Pilch-Kowalczyk

Department of Radiology, Medical University of Silesia,

Katowice, Poland

M. Kohut

Department of Gastroenterology, Medical University of Silesia, Katowice, Poland secondary to restricted diet appeared several years ago. She underwent appendectomy at the age of 1 year. She had been previously diagnosed in other departments, and based on colonoscopy, dolichocolon had been suggested. Physical examination revealed a large abdominal mass and cachexia $\left(\mathrm{BMI}=15.5 \mathrm{~kg} / \mathrm{m}^{2}\right)$. A plain abdominal X-ray showed a round radiolucent air-filled cyst. Barium enema revealed a single, large diverticulum of the transverse colon (Fig. 1). Laparotomy showed a giant diverticulum originating from the proximal part of the transverse colon that was $40 \mathrm{~cm}$ long, $10-15 \mathrm{~cm}$ wide at the bottom and $4-5 \mathrm{~cm}$ wide at the gate (Fig. 2). The right half of the colon was dilated and had flabby walls. An extended right hemicolectomy with primary end-to-end anastomosis was performed. Histopathology revealed that the giant diverticulum contained all four layers of the normal bowel wall (Fig. 3). The postoperative course was uneventful, and she was discharged in 1 week without any complications.

\section{Discussion}

A giant colonic diverticulum (GCD) is defined as a colonic diverticulum measuring $4 \mathrm{~cm}$ or larger. ${ }^{1,2}$ It is a very rare condition, and most frequently, it is associated with colonic diverticular disease. More than $90 \%$ of giant colonic 


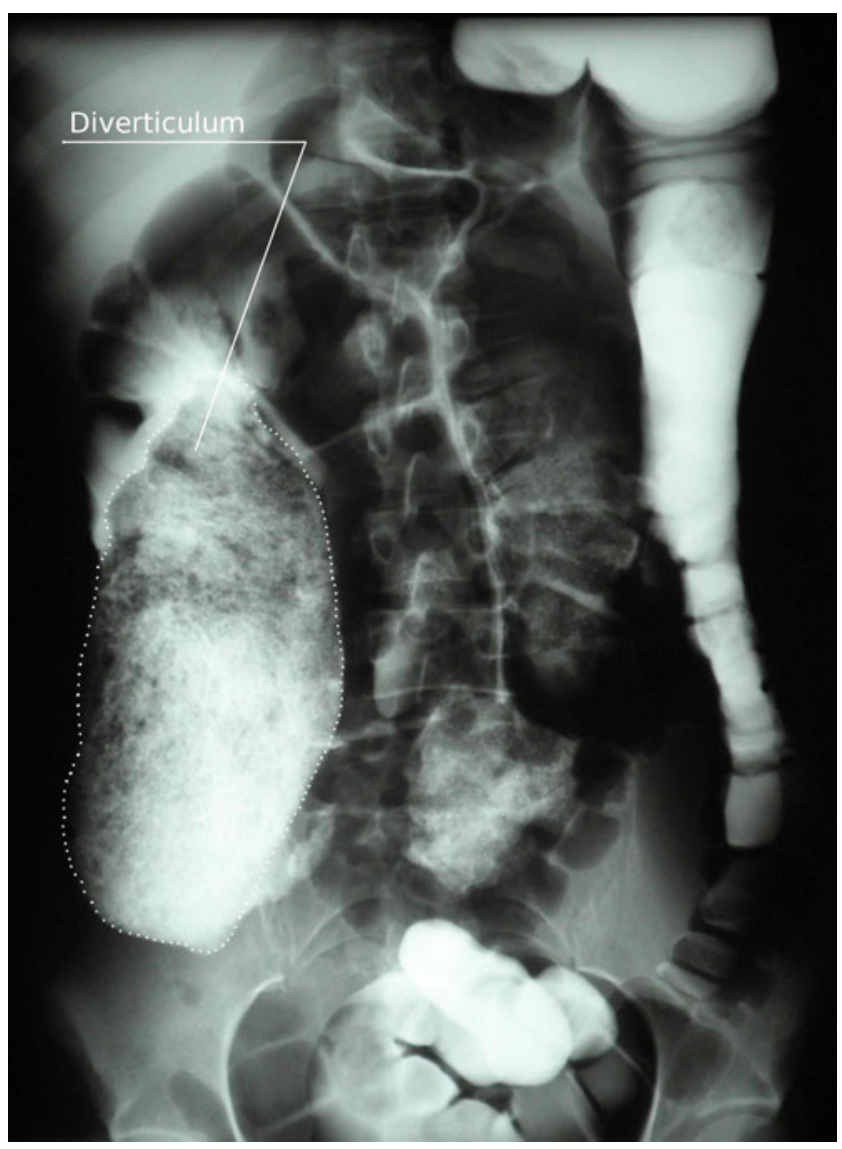

Fig. 1 Barium enema showing a giant diverticulum of the transverse colon

diverticula are found in the sigmoid colon. GCD was described first in 1953 by Hughes and Greene, ${ }^{3}$ primarily as a "solitary air cyst". Different names ("giant air cyst" or "giant cyst") have been used to describe this condition. According to Steenvoorde et al., ${ }^{2}$ the term "giant colonic diverticulum" is preferred. Pathologically, GCD is divided into three types: type I (22\%), pseudodiverticulum composed of granulation and fibrous tissue, with chronic inflammatory cells and remnants of muscularis mucosa; type II (66\%), inflammatory diverticulum arising from local perforation and communicating with an abscess cavity and type III (12\%), true diverticulum that contains all the layers of normal bowel wall and being in continuity with the gut lumen. ${ }^{2,4}$ Giant diverticulum located in the transverse colon is extremely rare. ${ }^{5-7}$ Only one case of a true giant diverticulum of the transverse colon that was accompanied by a right inguinal hernia of the greater omentum has been reported in the literature. ${ }^{5}$

We present the unique case of an uncomplicated true giant diverticulum of the transverse colon. Because symptoms have been remaining from patient's childhood, we believe that this pathology can be congenital due to an intestinal duplication.
GCD may be asymptomatic or presents with nonspecific symptoms, such as vague abdominal pain, constipation, rectal bleeding, nausea and vomiting, abdominal distension, diarrhoea and abdominal mass. ${ }^{2}$ In $28 \%$ of patients, complications such as inflammation, perforation, intraabdominal abscess formation and wall infarction occur. A $2 \%$ risk of carcinoma developing inside diverticulum has been reported in the literature. ${ }^{4}$ A plain supine abdominal $\mathrm{X}$-ray is the radiological investigation of choice for GCD diagnosis. ${ }^{2}$ Preoperative diagnosis may also include barium enema, CT scan or MRI. ${ }^{5,8}$

Diverticulectomy in selected cases or partial colectomy with the diverticulum is the preferred method of treatment in uncomplicated GCD. In complicated cases, a two-stage resection with Hartmann procedure is necessary. ${ }^{8}$

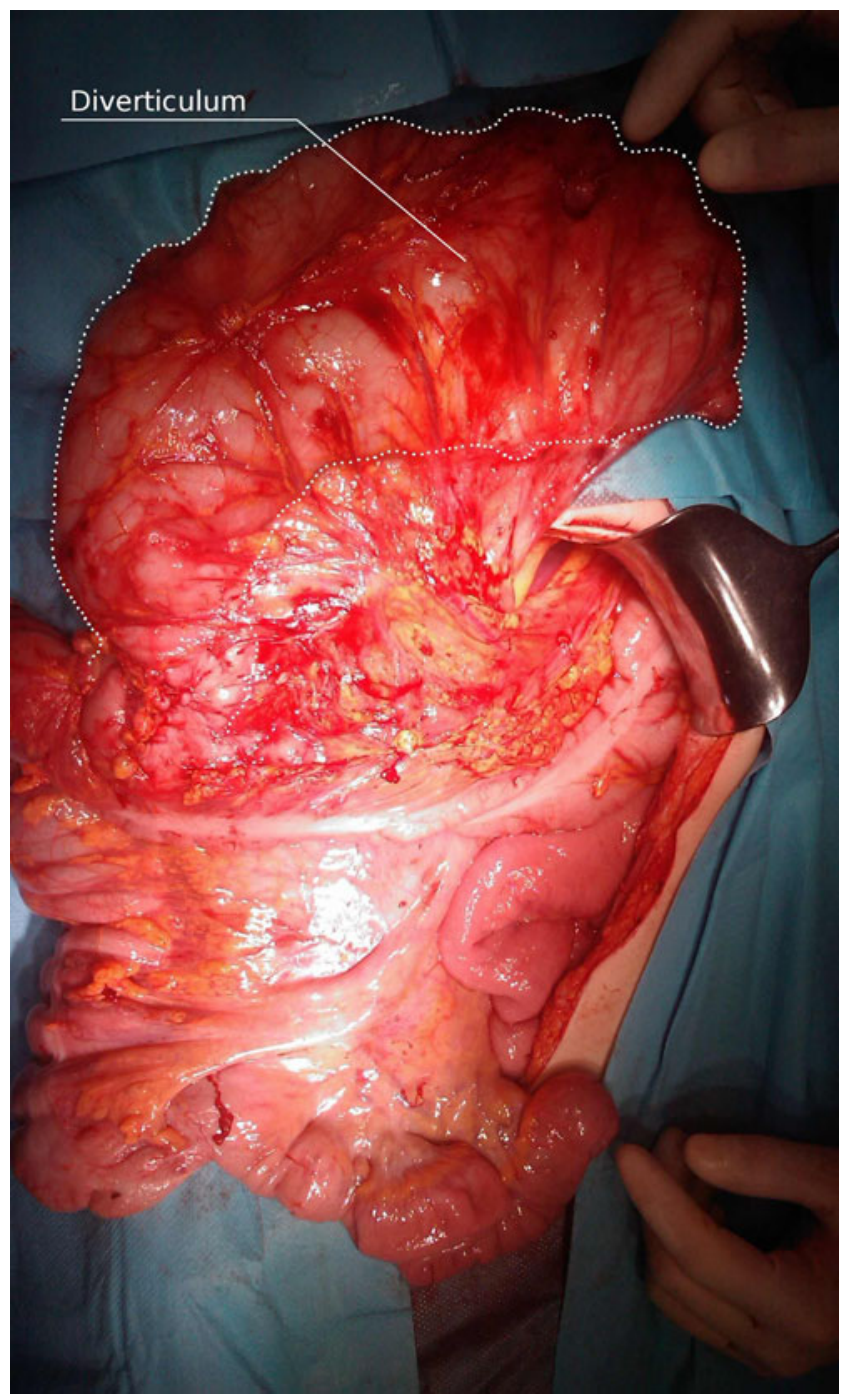

Fig. 2 Intraoperative image demonstrating a giant diverticulum of the transverse colon 
Fig. 3 Histopatological examination - a giant diverticulum contains all four layers of the normal bowel wall

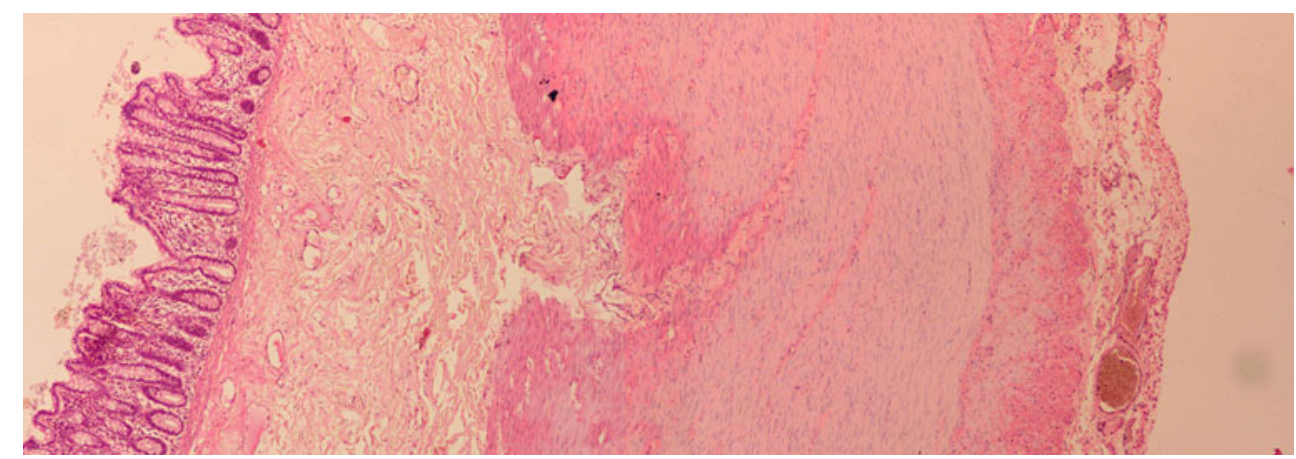

Open Access This article is distributed under the terms of the Creative Commons Attribution Noncommercial License which permits any noncommercial use, distribution, and reproduction in any medium, provided the original author(s) and source are credited.

\section{References}

1. Choong CK, Frizelle FA. Giant colonic diverticulum: report of four cases and review of the literature. Dis Colon Rectum 1998, 41: $1178-1185$.

2. Steenvoorde P, Vogelaar FJ, Oskam J, Tollenaar RA. Giant colonic diverticula. Review of diagnostic and therapeutic options. Dig Surg 2004; 21: 1-6.
3. Hughes WL, Greene RC. Solitary air cyst of peritoneal cavity. AMA Arch Surg 1953; 67: 931-936.

4. Custer TJ, Blevins DV, Vara TM. Giant colonic diverticulum: a rare manifestation of a common disease. J Gastrointest Surg. 1999; 3(5): 543-548.

5. Yoon SE, Lee YH, Yoon KH, Kim EA, Choi SS, Juhng SK, Yun KJ, Park WC. Complicated giant diverticulum of the transverse colon accompanied by right inguinal hernia of the greater omentum. Br J Radiol. 2007; 80(957): e201-e204.

6. Sagar S. Giant solitary diverticulum of the transverse colon with diverticulosis. Br J Clin Pract 1973; 27: 145-146.

7. Wallers KJ. Giant diverticulum arising from the transverse colon of a patient with diverticulosis. Br J Radiol 1981; 54: 683-688.

8. Toiber-Levy M, Golffier-Rosete C, Martinez-Munive A, Baquera J, Stoppen ME, D’Hyver C, Quijano-Orvañanos F. Giant sigmoid diverticulum: case report and review of the literature. Gastroenterol Clin Biol 2008; 32: 581-584. 